\title{
Der Freiheitsbegriff in Argentinien (1750 - 1850): Von den Einzelfreiheiten (libertates) zur Freiheit des Einzelnen (libertad)?
}

\author{
Von Andreas Timmermann, Berlin*
}

\section{Einleitung}

Reinhart Koselleck zufolge kennzeichnen die Begriffs- und Institutionengeschichte der von ihm so bezeichneten „Sattelzeit“ gesellschaftliche, politische und kulturelle Brüche, in deren Folge sich seit Mitte des 18. Jahrhunderts die Bedeutung klassischer topoi wandelte. Um den Übergang des Alten Staates zum Staat der Moderne sprachlich erfassen zu können, analysierte er Schlüsselbegriffe der politischen Ordnung. In diesem Zusammenhang konstatiert er einen Wechsel von pluralen zu singularen Begriffen, was neben dem Terminus „Staat“ speziell für das Freiheitsverständnis gelte: Die „Freiheiten“ und kollektiven Privilegien einzelner Gruppen und Körperschaften weichen nach und nach einem universalen Konzept von Freiheit, das jedem Einzelnen individuelle Freiheit verheißt. Weltanschaulich hat diese Verheißung in Europa ebenso wie in Lateinamerika der Liberalismus proklamiert, um ,das Recht des Einzelnen als ein Recht im Singular - als Freiheit statt Freiheiten - zu dem Ausgangspunkt zu machen, aus dem alle weiteren dann nur noch negativ zu formulierenden Konsequenzen folgen“ (Michael Zöllner). Wenn aus diesem Recht des Einzelnen alle Freiheiten und Abwehrrechte folgen, dann ist streng genommen sogar deren gesonderte Aufzählung entbehrlich. Umgekehrt können Kollektive dann nur solche, hier im Plural zu formulierende Befugnisse besitzen, die Ihnen die Einzelnen gewähren, wenn sie diese nicht den Individuen weggenommen haben. Diese Folgerung schwächt die historische Stellung der Korporationen als Träger besonderer Rechte, worauf im folgenden noch näher einzugehen ist.

Auch die Lateinamerika behandelnde Historiographie beurteilt die Zeit von 1750 bis 1850 als Schlüsselepoche und rekurriert dabei vereinzelt auf das Konzept der „Sattelzeit“. Dies lässt sich damit erklären, dass infolge der Französischen Revolution und der Unabhängigkeitsbewegung in Nordamerika neue Konzepte in die Debatten der kreolischen Eliten Eingang fanden und die politischen und gesellschaftlichen Erfahrungen gerade zu

Andreas Timmermann, Dr. jur. and historian, working for the state chancellery of SchleswigHolstein/Germany. Assistant to the plenipotentiary concerning questions of Bundesrat and of Economics, preparing the controversial items on the Bundesrat agenda. Holds venia legendi for southwest-european and latinamerican history at the University of Erfurt.

E-Mail: andreas.timmermann@ lv.landsh.de

Der Aufsatz ist die erweiterte Fassung eines Referats, das der Autor am 27.6.2009 in Kassel vor dem Arbeitskreis für Überseeische Verfassungsvergleichung gehalten hat. 
einem Zeitpunkt beeinflussten, als sich die lateinamerikanischen Provinzen vom Mutterland emanzipierten. ${ }^{1}$ Um diesen Ansatz weiter zu verfolgen, sei anhand eines jener Schlüsselbegriffe (Freiheit) und am Beispiel eines Landes (Argentinien) darauf eingegangen, ob und unter welchen Bedingungen ein solcher Übergang auch in Übersee zu beobachten ist; und zwar in derjenigen überseeischen Provinz eines europäischen Königreiches (Spanien), die spätestens nach ihrer Unabhängigkeit eine eigenständige politische, sozio-ökonomische und kulturelle Entwicklung genommen hat.

Wenn im Folgenden auf einen bestimmten Wortgebrauch und seine Verbreitung abgestellt wird, kann es in jedem Fall nur um Tendenzen und um eine Annäherung gehen. Denn gerade in Argentinien und vor allem im politisch-gesellschaftlichen Bereich ist eine besondere Vielfalt und Unregelmäßigkeit der Begriffswahl zu beobachten. Dies illustriert etwa der Umstand, dass argentinische Staatsmänner noch im zweiten und dritten Jahrzehnt des 20. Jahrhunderts bisweilen auf den mittelalterlichen Begriff der alten spanischen „fueros“ (Sonderrechte) abstellten. ${ }^{2}$ Also zu einem Zeitpunkt, da dieser Pluralbegriff längst nicht mehr die politischen, gesellschaftlichen oder kulturellen Erfahrungen widerspiegelte unabhängig davon, wie der Gebrauch gemeint war: sei es als bloßes Stilmittel und aus Freude am Formulieren, sei es als Ausfluss eines auch in Übersee immer wieder modischen Historismus. Oder aber waren die Wurzeln des mittelalterlich-spanischen Korporatismus so stark, dass sich über die Mitte des 19. Jahrhunderts hinaus ein modernes Freiheitskonzept nicht durchsetzen konnte?

\section{Der theoretische Ansatz: Einzelfreiheiten versus Freiheit des Einzelnen}

Dass sich im 18. Jahrhundert neue Begriffe häuften, die die alte in eine neue Wirklichkeit transformieren halfen, erklärt Reinhart Koselleck mit der revolutionären Umbruchsituation der erwähnten „Sattelzeit“: Bisher geläufige Worte verloren nun ihre innovative Kraft. Erst der kollektiv-singulare Begriff, der mit dem alten Wort transportiert worden sei, habe vor den nun anderen Erfahrungshorizonten der Zeitgenossen neue Innovationspotentiale frei gesetzt. Exemplarisch nennt er die Umformung älterer Wortinhalte zu den Begriffen „Staat“

1

Ursula Heimann, Liberalismus, ethnische Vielfalt und Nation. Zum Wandel des Indio-Begriffs in der liberalen Presse in Mexiko, 1821-1876, Stuttgart 2002, S. 23 f, m.w.N. zur Historiographie.

Bezogen auf die Rechte und die Souveränität Argentiniens der Präsident der Republik, Hipólito Yrigoyen, im Schreiben an Emilio Giménez Zapiola vom 15.7.1918, abgedruckt in: ders., Documentos, Buenos Aires 1949, S. 93; ders., Nachricht an Botschafter Marcelo T. de Alvear vom 30.12.1920, in: Documentos, S. 166. 
und „Freiheit“, die seit der Aufklärung eine zuvor beispielslose Kraft und Dynamik entfalteten. $^{3}$

Demnach stellt sich der Zusammenhang für diese beiden Begriffe wie folgt dar, wobei stets einschränkend zu berücksichtigen ist, dass die Ereignisgeschichte so wechselhaft und immer wieder anders verläuft, weshalb die neuen, übergreifenden Interpretationen die Wirklichkeit nur unzureichend abbilden können: Aus dem hohen oder späten Mittelalter stammte eine ständische Vielfalt an Rechten, Ehren, Privilegien, Freiheiten, Lasten oder Pflichten, die sich bis ins 18. Jahrhundert im Begriff Status, nämlich Stand spiegelte. Da „Status“ im Sinne von Stand eine legal ein- und ausgrenzbare Teilgruppe meinte, die andere ebenso ein- und ausgrenzbare Teilgruppen voraussetzte, zielte er auf eine rechtlich heterogene, in sich plurale, sozial und politisch ungleiche Gesellschaft. Erst als der Stand zum Störfaktor der eigentlichen Staatsbildung wurde und der moderne Verwaltungsstaat diese ständischen Unterschiede nach und nach einebnete und schließlich aufhob, entstand mit zunehmender Rechtsgleichheit die moderne (Klassen)gesellschaft des 19. Jahrhunderts. ${ }^{4}$ Wie demnach der übergeordnete Begriff im Plural (Stände) allmählich dem Singular (Staat) wich, häuften sich seit dem 18. Jahrhundert weitere, damit zusammenhängende neue Kollektivsingulare, die die alte in eine neue Wirklichkeit transformieren halfen, darunter die Freiheit: „Aus den konkreten Geschichten wird die Geschichte an sich, aus den sachbezogenen einzelnen Fortschritten wird der Fortschritt selber, aus den Freiheiten ständischer Vorrechte wird die allen gemeinsame Freiheit, die seitdem durch immer neue Epitheta bestimmt werden muss (sozial, ökonomisch, in einem alten und auch neuen Sinn christlich, politisch usw.), um konkreten Sinn zu gewinnen“. ${ }^{5}$ Dieser und die anderen neuen Leitoder Grundbegriffe haben gemeinsam, dass sie nicht mehr nur bestimmte Erfahrungen widerspiegeln, sondern einen Verfassungswandel in sozialer, politischer, religiöser Hinsicht ausdrücken. ${ }^{6}$

Dieser moderne Freiheitsbegriff ist demnach nicht bloß die Quersumme der ständischen Freiheiten, die sich historisch zu einem Kollektivsingular verdichtet und auf alle Bürger ausgedehnt haben. Sie findet vielmehr eine neue Grundlage im Anspruch der Individuen, die zu ihrer Sicherheit Gewaltentrennung, politische Mitwirkung und Anerkennung der

Reinhart Koselleck, Begriffsgeschichten. Studien zur Semantik und Pragmatik der politischen und sozialen Sprache, Frankfurt am Main 2006, S. 67, 333; ebenso Hans Ulrich Gumbrecht, Dimensionen und Grenzen der Begriffsgeschichte, München 2006, S. 22 f.

Reinhart Koselleck, Begriffsgeschichten (Fn. 3), S. 65, 67.

5 Reinhart Koselleck, Einleitung, in: Otto Brunner / Werner Conze / Reinhart Koselleck (Hg.), Geschichtliche Grundbegriffe. Historisches Lexikon zur politisch-sozialen Sprache in Deutschland, Bd. 1, 5. Aufl., Stuttgart 1997, S. XVII.

6 Reinhart Koselleck, Die Geschichte der Begriffe und Begriffe der Geschichte, in: Carsten Dutt (Hg.), Herausforderungen der Begriffsgeschichte, Heidelberg 2003, S. 7 ff. 
Menschenrechte einfordern. ${ }^{7}$ Schließlich ist wie „Staat“ auch der Grundbegriff „Freiheit“ der Gesetzessprache zuzuordnen, weil er einen Allgemeinheitsanspruch erhebt und mit den unterschiedlichsten Einzelfällen in Übereinstimmung zu bringen ist, ohne darüber die generelle Geltung und den Charakter einer juristisch zwingenden Anweisung an Legislative und Exekutive zu verlieren. Freiheit schlechthin - im Singular - ist nun etwas anderes als eine von mehreren konkreten Freiheiten in Form des Privilegs. ${ }^{8}$

\section{Ausgangsbedingungen}

a. Das spanische Foralrecht: Wenn es um „Einzelfreiheiten“ geht, nämlich jene im Plural zu formulierenden Befugnisse, die noch während des 18. Jahrhunderts im spanischen Reich galten, sind diese bis auf die mittelalterlichen Rechtsverbürgungen in ihrem institutionellen und korporativen Sinne zurückzuverfolgen: auf die alten Sonderrechte (fueros) und auf die spezifischen Vorrechte der Gemeinden (libertades comunales). „Fueros“ meinen Sonderrechte, die der König gewährte (cartas de privilegio), und Befreiungen von öffentlichen Lasten, insbesondere von Abgaben (franquezas, exenciones de gabela). Hierunter fielen auch Schenkungen (cartas pueblas) und Gunstbezeugungen (gracias) des (Lehns)herrn. Ort dieser „Freiheiten“ waren häufig die Städte. Sie galten als wesentliches Element der Territorialordnung und verfügten über einen ausgedehnten Jurisdiktionsbezirk (alfoz) auf dem Land. $^{9}$

Die Gemeinden genossen zeitweise weitreichende Stadtrechte. Mit den gewährten Sonderrechten waren für die begünstigten Städte oder Marktflecken zugleich die Anerkennung einer Lehnspflicht, mindestens aber eines Treueversprechens und konkrete Lasten verbunden, insbesondere Geldleistungen und militärischer Beistand. ${ }^{10}$ Die Stadtrechte beruhten auf einer feudalen Gesellschaftsordnung und einem „Pluralismus von Zellstrukturen“, der sowohl im römischen Munizipium wie auch im germanischen Lehen wurzelte. Satzungen und Privilegien gewährten eine relative Immunität, deren tatsächliche Reich-

Artikel „Freiheit“, in: Otto Brunner / Werner Conze / Reinhart Koselleck (Hg.), Geschichtliche Grundbegriffe. Historisches Lexikon zur politisch-sozialen Sprache in Deutschland, Bd. 2, 4. Aufl., Stuttgart 1998, S. 488.

Reinhart Koselleck, Begriffsgeschichten (Fn. 3), S. 331.

Peer Schmidt, Freiheit und Freiheitsvorstellungen im frühneuzeitlichen Spanien im Spannungsfeld von imperialer Monarchie, Kommune und Individuum, in: Georg Schmid / Martin van Gelderen / Christopher Snigula (Hg.), Kollektive Freiheitsvorstellungen im frühneuzeitlichen Europa (1400 1850), Frankfurt/Main 2006, S. 295 ff., speziell S. 297 f.

10

Näher dazu die bis heute vorbildliche vergleichende Darstellung bei Francisco Martínez Marina, Ensayo histórico-crítico sobre la legislacíon y principales cuerpos legales de los Reinos de León y Castilla, especialmente sobre el Código de las Siete Partidas de don Alfonso el Sabio (1808), 4. Buch, Rn. 1 ff., in: ders., Obras escogidas, Bd. 1, Madrid 1966, S. 66 ff. 
weite von den Machtbefugnissen des Lehnsherren abhing. ${ }^{11}$ Grenzen ergaben sich zudem aus der Natur des Privilegs oder Sonderrechts, das immer auch den Charakter eines Gnadenerweises hatte. Der Sonderrechtsstatus der Städte korrespondierte mit dem Verhältnis der Untertänigkeit und Abhängigkeit (modus subjectionis), wie es für die mittelalterliche Ordnung insgesamt kennzeichnend war. Insgesamt unterschied sich das mittelalterliche spanische Foralrecht kaum von den Freiheiten, auf die sich die Freien Städte in Mitteleuropa beriefen. Die Urkunden der Monarchen wurden regelmäßig an ein allgemeines, römisch-rechtlich gefärbtes Rechtsverständnis zurückgebunden. Wenn ein Privileg auf abweichende Rechtsauffassungen stie $\beta$, musste sich seine Reichweite in der Auseinandersetzung mit konkurrierenden Kräften, etwa der Kirche erst erweisen. ${ }^{12}$ Dies alles verdeutlicht, dass es keineswegs bereits um individuelle Rechtsverbürgungen in einem liberalstaatlichen Sinne ging.

Nichts anderes gilt für das teilweise recht fortschrittliche Foralrecht, etwa in Aragón, soweit es sich auf den Schutz der Einzelnen bezog: Zwar bildeten die verschiedenen Verfahren, um Rechtsstreitigkeiten zu schlichten, einen beachtlichen Schutz; so das Verfahren wegen widerrechtlicher Handlungen (agravios, greuges), die „Unterschriftsverfügung“ (firma de derecho) und die Auslieferungsanordnung (manifestación de personas). ${ }^{13}$ Jedoch wurzelten diese Verfahren in einem ständischen, kollektiven Privileg, ausgehend von den Fueros de Ejea (1265), und bildeten viel mehr als eine subjektiv-rechtliche Garantie ein institutionelles Gegengewicht innerhalb der Stände. Ganz abgesehen davon, dass die Wirksamkeit von persönlichen und von politischen Umständen abhing, die am Ende des 16. Jahrhunderts zum Niedergang dieser Einrichtungen führten. ${ }^{14}$

Rechtsgeschichtlich finden sich jedenfalls für das spanische Reich vergleichbare Ausgangsbedingungen zu jenen, die Koselleck voraussetzt: Seit dem Mittelalter sind in Gestalt der Fueros und Grundgesetze (leyes fundamentales) Freiheitsverbürgungen bekannt. Allerdings gelten diese für einen begrenzten territorialen oder gesellschaftlichen Raum, wofür auch die Freiheitsbriefe stehen, die sich die Cortes von León bestätigen ließen (1188). Daraus ergaben sich zwar Freiräume und eine zeitweise wirksame Hemmung willkürlicher Machtausübung, soweit vertrags- oder gewohnheitsmäßig wechselseitige Rechte und

Luis Sánchez Agesta, Der Staat bei Bodin und in der spanischen Rechtsschule, in: Der Staat 16 (1977), S. 361.

12

Peter Moraw, Zur Verfassungsposition der Freien Städte zwischen König und Reich, besonders im 15. Jahrhundert, in: Der Staat: Beiheft 8 (1988), S. 15.

13 Victor Fairen Guillen, Die Aragonesischen Verfassungsprozesse: Wesen und Entwicklung, Herkunft und Verbreitung, in: Zeitschrift der Savigny-Stiftung für Rechtsgeschichte 91 (1974), S. 117 ff., speziell S. 138 .

14 Andreas Timmermann, Die „Gemäßigte Monarchie“ in der Verfassung von Cádiz (1812) und das frühe liberale Verfassungsdenken in Spanien, Münster 2007, S. 244 f. 
Pflichten anerkannt waren. Diese beruhten jedoch auf einem personalistischen, lehnsrechtlichen Verhältnis und dem Gedanken der Wechselseitigkeit, wie er im möglichen Rechte bzw. Lehnsentzug auf der einen oder der Gefolgschaftsverweigerung auf der anderen Seite zum Ausdruck kam.

b. Die Sonderrechte in Argentinien: Neben den ständischen Freiheiten (libertates), die als Schutzpositionen für Individuen und Korporationen rechtlich und politisch zumeist fest umrissen waren, wird seit der frühen Neuzeit „Freiheit“ (libertas) in der Theologie und Philosophie immer häufiger erwähnt, ohne dass sich diese bereits in eine allgemein gültige Freiheit umsetzen oder rechtlich fassbar im politischen Raum artikulieren ließ. Häufig bezeichnete „Freiheit“ dann noch den Inbegriff von Freiheiten, die dem jeweiligen Stand zukamen, wie die spezifische Libertät der Landstände, ohne dass dies bereits zu einer Transzendierung der Einzelfreiheiten führte. ${ }^{15}$ In politischer Hinsicht gilt dies auch für den Aufstand der Comunidades von Kastilien (1520 - 1521) - nach der Inthronisierung Karls I. von Spanien, des bald zum Kaiser erhobenen Karl V. Unter dem Schlagwort „Libertät“ (libertas) im Singular meinten die Gemeinden ihre alten ständischen Sonderrechte, v.a. der Steuereintreibung und Selbstregierung, aber noch keine universale oder individuelle „Freiheit" im neuzeitlichen Sinne. ${ }^{16}$ Gegenüber den als partikularistisch empfundenen fueros und Stadtrechten hatte bereits seit dem 14. Jahrhundert eine unitarische Tendenz an Boden gewonnen, so dass die Krone in Kastilien den Gemeinderat aufhob, einen königlichen Oberbefehl (regimiento) einführte, die Gemeindeverwaltung auf eine zumeist adlige Oligarchie übertrug und damit die Selbstverwaltung sowie die vermeintlichen Vorläufer einer „bürgerlichen Freiheit“ abbaute. Nicht nur die Wahl des Magistrats, der militärischen Befehlshaber und der Gemeindevertreter für die Cortes büßte den demokratischen Charakter ein. Auch die Beteiligung der Bürger an den kommunalen Angelegenheiten insgesamt wurde erschwert. Hierin und nicht erst in der Auseinandersetzung König Karls I. liegen der eigentliche Einschnitt und die Weichenstellung zugunsten einer zentralistischen, aristokratisch geprägten Gemeindeverfassung. ${ }^{17}$

Die Blütezeit des freien Städtetums war daher bereits vorüber, als die Kolonisation in Übersee begann, wo sich die Organisation der neu gegründeten Städte nach der spanischen Gemeindeordnung richtete. Diese erlangten dort niemals eine der spanischen Rechtstradi-

Artikel „Freiheit“, in: Otto Brunner / Werner Conze / Reinhart Koselleck, Geschichtliche Grundbegriffe, Bd. 2 (Fn. 7), S. 470.

Dazu m.w.N. Peer Schmidt, Freiheit und Freiheitsvorstellungen im frühneuzeitlichen Spanien im Spannungsfeld von imperialer Monarchie, Kommune und Individuum (Fn. 9), S. 302 f.

17

José Martínez Cardos, Vida y obra de Dr. Don Francisco Martínez Marina, in: Francisco Martínez Marina, Obras escogidas, Bd.1, S. XLVIII, L f; Andreas Timmermann, Die „Gemäßigte Monarchie“ (Fn. 14), S. 249 f. 
tion entsprechende Selbstverwaltung oder nahmen eine wirklich demokratische Vertretung aller Bewohner wahr. Für die hier gestellte begriffsgeschichtliche Frage ist jedoch festzuhalten, dass in den Gebieten des heutigen Argentiniens die Sonderrechte (fueros, cartapueblas) und Freiheiten (libertades) der Gemeinden geläufig waren. Auch wurden sie von den Kreolen stets in jenem institutionellen und korporativen Sinne verstanden, zumal das städtische Foralrecht die gesamte Kolonialzeit überdauerte. Wenn danach die argentinische Historiographie diese „Freiheiten“ (im Plural), insbesondere was die Selbstverwaltung des Gemeinderats (Cabildo) und die Gerichtshoheit anbelangt, immer wieder stark überhöht und in ihrer praktischen Anwendung allzu weit reichend dargestellt hat, so spricht dies nicht gegen, sondern eher für die Verwurzelung in der argentinischen Begriffswelt. ${ }^{18}$ Hinzu kam die Schlüsselerfahrung der Siedler, gerade in den besonders abgelegenen Gebieten auf sich allein gestellt zu sein und einen vielfach weniger beschränkten Gebrauch von den erwähnten Freiheiten machen zu können als in den Zentren des Kolonialreiches. So hat die Krone in der peripheren Provinz Río de la Plata den Stadtansässigen (Vecinos) und Konquistadoren teilweise umfassendere Privilegien eingeräumt als in anderen Teilen Spanischamerikas. Das war allerdings mit den besonderen Verhältnissen der Conquista zu erklären, so dass die Kreolen daraus keine dauerhaften rechtlichen oder politischen Ansprüche ableiten konnten. ${ }^{19}$

Schließlich sind weitere Körperschaften hervorzuheben, wenn es um jene ständischen Einzelfreiheiten (libertates) spanisch-mittelalterlicher Provenienz in Argentinien geht. Hierbei handelt es sich um jene drei Säulen des traditionellen hispanischen Korporativismus, die unter den besonderen Bedingungen der halbfeudalen überseeischen Ordnung ihre ohnehin großen politischen und wirtschaftlichen Freiräume wahren, wenn nicht ausbauen konnten. ${ }^{20}$ Zum einen die Armee, die im Fuero militar über zahlreiche Privilegien und Exemtionen verfügte, auch um Anreize zum Militärdienst zu schaffen. Milizangehörige, die zum Kriegsdienst oder zu längeren Übungen einberufen wurden, unterstanden der Militärgerichtsbarkeit und blieben von der ordentlichen Jurisdiktion befreit. ${ }^{21}$ Zum anderen die Kirche, die v.a. in den weitgehend unabhängigen Missionsstationen der Jesuiten im Landesinneren, so am Oberlauf der Flüsse Uruguay und Paraná, zeitweise weitreichende, auto-

Ausführlich m.w.N. zur Debatte: José Rafael López Rosas, Historia constitucional argentina, 5. Aufl., Buenos Aires 2002, S. 22 ff.; für Spanischamerika insgesamt: Otto Carlos Stoetzer, Las raíces escolásticas de la emancipación de la América española, Madrid 1982, S. 14 ff.

Vgl. instruktive das Beispiel bei: Richard Konetzke, Süd- und Mittelamerika I. Die Indianerkulturen Altamerikas und die spanisch-portugiesische Kolonialherrschaft, 17. Aufl., Frankfurt am Main 1999, S. 142 f.

Howard J. Wiarda, Corporatism and comparative politics. The other great "ism", New York 1996, S. $78 \mathrm{f}$.

21 Zu diesem Institut: Richard Konetzke, Süd- und Mittelamerika I (Fn. 19), S. 162 f. 
nome Befugnisse wahrnahm. Die Privilegien der dritten dieser Säulen des argentinischen Korporativismus, der kreolischen Oligarchie, waren insbesondere im Andenraum erdrückend. In den Städten und auf dem Land sicherten sich die Kreolen u.a. das Vorrecht, über Eigentum zu verfügen, sie kontrollierten die Arbeitsbeziehungen und genossen Abgabenbefreiungen. Bis zum Ende des 18. Jahrhunderts hatte sich ein Kastensystem entwickelt, das der nicht-weißen Bevölkerung dauerhaft einen niederen gesellschaftlichen Status in der Hierarchie zuwies. 22

c. Das christliche Naturrecht: Ideengeschichtlich ist ferner die spanische Moraltheologie des 16. Jahrhunderts von Bedeutung: Sie schuf eine gewisse Grundlage für den späteren Schutz individueller Rechte in Übersee, insofern sie den Begriff der ,natürlichen Freiheit“ (libertad natural) in zwei Richtungen entwickelte: einerseits gegen die politische Herrschaft, andererseits gegen Sklaverei und Leibeigenschaft. Die Tradition der Scholastik und des christlichen Naturrechts war in Argentinien ebenso unangefochten wie im übrigen Spanischamerika, woran auch das Vordringen der Aufklärung zunächst wenig änderte. ${ }^{23}$ So wurde noch in der zweiten Hälfte des 18. Jahrhunderts die offiziellen Lehrpläne mit dem Hinweis angekündigt, dass sie „exakt der Lehre des Heiligen Augustinus und des Heiligen Thomas folgen“. ${ }^{24}$ Diese Lehre vertraten in Übersee maßgeblich die geistlichen Orden, in zwei leicht abweichenden Varianten: Während die Dominikaner und Augustiner besonders die klassische Schule des Thomas von Aquin lehrten, betonten die Jesuiten stärker das erweiterte thomistische Denken der spanischen Schule von Salamanca und ihre vertragstheoretische Ausrichtung. Letztere Tendenz dominierte an der von den Jesuiten geführten Universität von Córdoba, wo die Schule von Salamanca bis zum Ende des 19. Jahrhunderts den stärksten Einfluss ausübte. Diese knüpfte an einen älteren, bereits im christlichen Mittelalter entwickelten Gedanken an: Der Mensch verfügt über bestimmte Rechte, die ihm deshalb keine irdische Gemeinschaft entziehen kann, weil er mit seiner menschlichen Würde (dignitas humana) gleichsam ,in das Gottesreich hineinragt“. Solche Rechte sind aber nur dann unabdingbar und unentziehbar, wenn eine überpositive Ordnung die königliche Gewalt begrenzt. Andernfalls, sofern nämlich die Fürsten selber diese höchste Ordnung bilden, kann es allenfalls noch darum gehen, ob diese Rechte leichter oder schwerer abzu-

David Rock, Argentina 1516 - 1982. From Spanish Colonization to the Falklands War, London 1986, S. $58 \mathrm{f}$.

Näher Otto Carlos Stoetzer, Las raíces escolásticas de la emancipación de la América española (Fn. 18), S. 41 ff., $188 \mathrm{ff}$.

24

Juan Baltasar Maziel, Informe al Gobernador del Río de la Plata, dado por el cabildo eclesiástico sobre el establecimiento de un colegio y de una Real pública universidad vom 5.12.1771, in: José Carlos Chiaramonte, Ciudades, provincias, Estados. Orígines de la Nación Argentina (18001846), Buenos Aires 1997, S. 285 f. 
ändern sind. ${ }^{25}$ Francisco de Vitoria stützte die unveräußerlichen Rechte der Menschen auf das natürliche und göttliche Recht (derecho natural y divino): Normen des menschlichen Rechts (derecho humano), die den Anweisungen dieser höherrangigen Ordnungen widersprächen, seien unmenschlich und vernunftwidrig, weshalb ihnen die Gesetzeskraft fehle. ${ }^{26}$ Francisco Suárez zufolge gehört es zur Natur des Menschen, dass er frei handeln kann. ${ }^{27}$ Diese Freiheit wird nur dann der naturgesetzlichen Bestimmung gerecht, wenn sie frei von äußerem Zwang ist und die Menschen nicht unfreiwillig, etwa unter Strafandrohung, dem Gesetz nachkommen. ${ }^{28}$

Trotz dieser Vorarbeiten im christlichen spanischen Naturrecht setzte sich erst im rationalen säkularen Naturrecht des späteren 17. Jahrhunderts die Vorstellung durch, wonach individuelle, in der Persönlichkeit gründende Rechte selber der Hoheitsgewalt Grenzen setzen können und - unter Wahrung der Souveränität - ein Raum der Privatheit und individuellen Entfaltung bleiben müsse, der absolut vor Eingriffen seiner Organe schütze. ${ }^{29}$ Noch weniger als in Spanien verfügten allerdings die Provinzen in Spanischamerika, so auch der Raum des Río de la Plata, über jene hierfür wesentlichen politisch-praktischen Erfahrungen, die das später auch im Süden nachgeahmte angelsächsische Freiheitskonzept prägten: der religiös inspirierte Kongregationalismus und die ausgeprägte Teilhabe der Siedler am öffentlichen Leben der Kolonien seit dem 17. Jahrhundert, die Besonderheiten der am englischen Vorbild orientierten Gemeinde- und Gerichtsverfassung, das Fehlen ständischer Privilegien, die Wirkung des englischen Naturrechts und das politische Selbstbewusstsein der Kolonisten gegenüber der englischen Krone. ${ }^{30}$ Diese Ausgangsbedingungen fehlten weitgehend Spanischamerika. Zu keinem Zeitpunkt in den drei Jahrhunderten der Kolonialisierung und an keinem Ort hatten sich dort „civil liberties“ und damit ein Schlüsselelement moderner Verfassungsstaatlichkeit entwickeln können. Dies änderte sich auch

Alfred Verdross, Die Würde des Menschen in der abendländischen Rechtsphilosophie, in: Joseph Höffner / Alfred Verdross (Hg.), Naturordnung in Gesellschaft, Staat, Wirtschaft, Innsbruck 1961, S. 355 .

Francisco de Vitoria, Relecciones sobre los indios y el derecho de la guerra (De Indis posterior sive de iure belli, 1539), 3. Aufl. Madrid 1975, 3. Teil, Ziff. 12, S. 90.

Francisco Suárez, Abhandlung über die Gesetze und Gott den Gesetzgeber (Tractatus de legibus et legislatore Deo, 1612), Freiburg 2002, 3. Kap., Ziff. 2, S. 55.

Francisco Suárez, (Fn. 26), 10. Kap., Ziff. 4 f., S. 498 ff.

29

30

Luis Sánchez Agesta, Principios de teoría política, 7. Aufl., Madrid 1986, S. 437.

Für viele: Horst Dippel, Die Amerikanische Revolution 1763 - 1787, Frankfurt am Main 1985, S. 18 ff.; Karl Löwenstein, Volk und Parlament nach der Staatstheorie der französischen Nationalversammlung von 1789. Studien zur Dogmengeschichte der unmittelbaren Volksgesetzgebung, München 1922, S. 46 ff.; ders., Verfassungsrecht und Verfassungspraxis der Vereinigten Staaten, Berlin 1959, S. 3 ff. 
nicht unter der aufgeklärten Herrschaft der Bourbonen in der zweiten Hälfte des 18. Jahrhunderts.

\section{Mai-Revolution (1810) und staatliche Emanzipation}

Trotz einer vom angelsächsischen „Muster“ abweichenden Entwicklung lässt sich in Argentinien seit dem ausgehenden 18. Jahrhundert ein allmählicher begriffsgeschichtlicher Übergang vom Konzept der ständischen Einzelfreiheiten (libertates) zur Freiheit des Einzelnen (libertad) feststellen, jedenfalls wenn wie hier die Aussagen prominenter Zeitgenossen und die zahlreichen amtlichen Dokumente der Emanzipationszeit zu Rate gezogen werden. Einen klaren Einschnitt bedeutete dann die Erhebung gegen den spanischen Regentschaftsrat im Jahr 1810: Seit Einsetzung der ersten Regierungsjunta am 25. Mai dieses Jahres spiegeln alle Dekrete, Statuten und Verfassungsentwürfe der nun folgenden exekutiven und legislativen Körperschaften ein grundlegend neues Freiheitskonzept wider. $^{31}$

a. Wirtschaftliche Freiheiten: Am Beginn dieses Übergang stehen die Reformmaßnahmen der spanischen Krone, hierin beeinflusst durch die französische Aufklärung und ihre Resonanz in Spanien: Abgesehen von Maßnahmen gegen Getreideknappheit und Steuererleichterungen, hob sie im Zuge der bourbonischen Reformen Handelsbeschränkungen auf, die auch die Ausfuhr und den Verkehr mit den überseeischen Provinzen betrafen, denen bis dahin durch das Handelsmonopol des Hafens von Cádiz enge Grenzen gesetzt waren. Wie diese Maßnahmen den praktischen Interessen der kreolischen Elite entsprachen, fanden die theoretischen Vorarbeiten Resonanz in Argentinien: Die Berater am Hofe verfochten nicht nur die Handelsfreiheit, sondern plädierten auch für die Berufsfreiheit und gegen das traditionelle System der Zünfte, Innungen und Bruderschaften. ${ }^{32}$ In Übersee gute Resonanz fand ein für die Madrider Wirtschaftsgesellschaft und im Auftrag der spanischen Regierung verfasster Reformentwurf: Gaspar Melchor de Jovellanos' „Bericht über das Agrargesetz“ (1795). Hierin behandelte er nahezu alle Gegenstände der Wirtschaftspolitik und Gesetzgebung, die trotz der erwähnten Reformmaßnahmen einer freieren Entwicklung von Landwirtschaft, Handel und Gewerbe im Wege standen: v.a. die Konzentration des Grund-

Dazu Ariosto D. González, Los Derechos del Hombre y del Ciudadano en el Río de la Plata 18101830, in: Academia Nacional de la Historia (Hg.), El pensamiento constitucional de Latinoamérica 1810-1830, Bd. 3, Caracas 1962, S. 147 ff., speziell S. 153 ff., mit einem guten Überblick über diese, sich rasch ablösenden Gremien in Buenos Aires und die von ihnen verabschiedeten einschlägigen Texte.

So der Graf von Campomanes, Pedro Rodríguez Campomanes, Discurso sobre el fomento de la industria popular (1774), Oviedo 1991, u.a. 15. Kap., S. 66 ff., zu den Nachteilen berufsständischer Sonderrechte für das Gewerbe; ferner ders., Discurso sobre la educación popular de los artesanos y su fomento (1775), Oviedo 1991, 17. Kap., S. $251 \mathrm{f}$. 
eigentums in den Händen der ökonomisch inaktiven Korporationen Gemeinden, Kirche, Adel, wodurch es dem Wirtschaftskreislauf entzogen und einem Großteil der Bevölkerung die Möglichkeit zu Bodenerwerb und Wirtschaftstätigkeit überhaupt genommen war. ${ }^{33}$ In Argentinien vertrat Manuel Belgrano noch vor der Unabhängigkeit die Belange eines freien Wirtschaftsverkehrs und stellte im Sinne Jovellanos' die Bodenfrage in den Mittelpunkt. ${ }^{34}$ Ferner sind hervorzuheben: Cornelio Saavedra y Rodríguez, der spätere Präsident der ersten argentinischen Regierung („Primera Junta de gobierno de las Provincias Unidas“, 1810), und der Publizist Manuel José de Lavardén: Sie wandten sich gegen die Sonderrechte des Adels, der Kirche und der Krone und plädierten für einen freieren Arbeitsmarkt, Eigentums- und Gewerbefreiheit. Ein weiteres Beispiel ist der liberale Geistliche Gregorio Funes aus Córdoba, der dank eines längeren Studienaufenthaltes im Spanien der 70er Jahre gut mit den neueren europäischen Reformansätzen vertraut war und sich in Argentinien entschieden für den Freihandel einsetzte. ${ }^{35}$

Als 1778 in Buenos Aires der „Freihandel“ verkündet wurde, entfielen die alten Handelslizenzen und viele der herkömmlichen Abgaben (palmeo, tonelada, San Telmo, extranjería, visitas). ${ }^{36}$ Nach den Handelserleichterungen begann am Río de la Plata ein offener Disput zwischen den Anhängern eines Handelsmonopols und den Befürwortern des Freihandels, die seit den 90er Jahren des 18. Jahrhunderts in immer neuen Eingaben den Abbau fortbestehender Handelshemmnisse forderten. Ein gutes Beispiel ist die Petition der Landwirte von 1793, vertreten durch die Handelskammer (Consulado) von Buenos Aires. Die Eingabe - unter Anführung der ,libertades“ noch im Plural - verrät den Einfluss der europäischen Physiokraten, welche die Freiheit des Einzelnen in Wirtschaft, Berufswahl und Eigentumsschutz betonten. ${ }^{37}$ Die Hoffnungen auf Freihandel nährte gegen Ende des 18. Jahrhunderts der Krieg zwischen Spanien und Frankreich, der dem Hafen von Buenos Aires den freien Handel mit den neutralen Staaten ermöglichte. Um so größer war jedoch die

Gaspar Melchor de Jovellanos, Informe de la Sociedad Económica de Madrid al Real y Supremo Consejo de Castilla en el expediente de Ley Agraria, in: ders., Espectáculos y diversiones públicas (1812) / Informe sobre la Ley Agraria (1795), 2. Aufl., Madrid 1998, S. 250 ff.

Manuel Belgrano, Medios generales de fomentar la agricultura, animar la industria y proteger el comercio en un país agricultor, Memoria vom 5.7.1796, in: José Carlos Chiaramonte, (Fn. 24), S. $293 \mathrm{ff}$.

M.w.N. zu den wichtigsten Reformschriften: Arturo Enrique Sampay, La evolución constitucional argentina, in: ders. (Hg.), Las Constituciones de la Argentina (1810 - 1972), Buenos Aires 1975, S. 8.

Nur die alcabala und der almojarifazgo überdauerten, allerdings mit deutlich niedrigeren Sätzen, David Rock, Argentina 1516 - 1982 (Fn. 22), S. 62.

„La vida económica (...) no debe amortiguarse con restricciones, sino aliviarse con libertades que sean compatibles con la justicia y con la pública utilidad“, Representación de los Labradores (1793), in: José Carlos Chiaramonte, Ciudades, provincias, Estados (Fn. 24), S. 292. 
Enttäuschung, als die spanische Krone 1802, nach dem Ende des Waffengangs, zur vorherigen Rechtslage zurückkehrte.

In Argentinien hat also zur Entwicklung des modernen Freiheitsbegriff beigetragen, dass die kreolischen Eliten weltanschaulich sowohl durch die ersten aufgeklärten Reformbemühungen der Krone wie auch durch die fortschrittlichen Lehren der französischen Enzyklopädisten, Physiokraten und Vertreter liberaler angelsächsischer Wirtschaftskonzepte beeinflusst waren. Allerdings dominierte bis zum Beginn des 19. Jahrhunderts dieser ökonomische Aspekt andere, in Europa wesentliche Elemente der Aufklärung, die dort im Zeitalter der Revolutionen zur Ablösung des ständischen Freiheitsbegriffs beigetragen hatte: In dem Maße, wie Scholastik und christliches Naturrecht weiterhin die Bildung und Weltanschauung der Kreolen prägten, konnte sich ,die Aufklärung“ in Spanischamerika nicht im Sinne jenes überwiegenden europäischen Epochenbegriffs aus dem 18. Jahrhunderts durchsetzen: Sie war hier viel weniger als dort eine „Geistesbewegung, durch die in einem alle menschlichen Lebensbereiche von Grund auf verändernden Säkularisationsprozess die moderne Welt heraufgeführt und eine umfassende Entzauberung der Welt eingeleitet wird“. ${ }^{38}$ Auch wesentliche, diesen Begriff konkretisierende Merkmale sind bis zur Mai-Revolution in Argentinien kaum nachzuweisen: Weder ein starkes Streben nach Emanzipation der Menschen ,aus der Welt des geschichtlichen Herkommens“, verstanden als Befreiung von Autoritäten, Ordnungen und Bindungen, noch ein durchgängiger Kampf gegen den ,kirchlichen Supranaturalismus“ waren in dieser Zeit charakteristisch. Dagegen ist durchaus ein neues Bewusstsein der Vernunftbegabtheit und geistigen Autonomie in der kreolischen Elite zu verzeichnen, wie es sich besonders im Aufschwung der wissenschaftlichen, literarischen und politischen Tätigkeiten im Zuge der Emanzipation niederschlug. ${ }^{39}$ Der Anteil der staatlichen Kulturpolitik hieran war allerdings begrenzt: Auch wenn die bourbonischen Reformen und reformorientierte Wirtschaftsgesellschaften (sociedades económicas) insgesamt günstigere Ausgangsbedingungen schufen, so erreichten die von der spanischen Metropole ausgehenden Impulse die überseeischen Gebiete in einem viel schwächeren Maße. ${ }^{40}$

Zu diesem zweiten Aspekt für Spanischamerika insgesamt: Guillermo Zermeño Padilla, Historia, experiencia y modernidad en Iberoamérica, 1750-1850, in: Jahrbuch für die Geschichte Lateinamerikas 45 (2008), S. 114 ff., speziell 130 ff.; Zu den genannten Merkmalen der Aufklärung: Horst Stuke, Aufklärung (Fn. 5), S. 245 f.

40

Arthur P. Whitaker, Enlightenment and spanish american independence, in: Academia Nacional de la Historia (Hg.), El movimiento emancipador de Hispanoamérica. Actas y ponencias, Bd. 4, Caracas 1961, S. 66; zur Rolle der Wirtschaftsgesellschaften: Robert Jones Shafer, The Economic Societies in the Spanish World (1763-1821), Syracuse 1958; speziell für Argentinien: S. 145 f., $239 \mathrm{ff}$. 
b. Politische Freiheit: Ein wichtiger Impuls für die Fortentwicklung des Freiheitsbegriffs war politischer Natur: Nachdem „Freiheit“ - betrachtet vom Erfahrungshorizont der Eliten aus - historisch zunächst die Freiheit des Handels (comercio libre) und die Befreiung von Beschränkungen des Wirtschaftsverkehrs bedeutet hatte, gewann der Begriff „libertad“ nach der Jahrhundertwende eine politische Bedeutung, befördert durch die Nachrichten von der Unabhängigkeit der Vereinigten Staaten: Der 1799 veröffentlichte „Brief an die Spanischamerikaner“ des peruanischen Jesuiten, Juan Pablo Viscardo y Guzmán, verband die scharfe Kritik an der Kolonialherrschaft und an der die überseeischen Provinzen benachteiligenden Wirtschafts- und Finanzpolitik mit dem Aufruf, die Unterdrückung nicht länger hinzunehmen und als ein natürliches Recht der Spanischamerikaner ihre Unabhängigkeit anzustreben. Als Vorbild führt er den Freiheitskampf der englischen Kolonien in Nordamerika an. ${ }^{41}$ Wenn dieser Aufruf und weitere frühe Dokumente, Berichte und persönliche Kontakte erst allmählich Widerhall in Argentinien fanden, schärften sie dennoch den politischen Sinn der elitären Zirkel, die ,rechtzeitig“ zur Erhebung von 1810 auf geeignete Vorlagen für die staatliche Emanzipation zurückgreifen konnten. Offenbar verfügte bereits die im Mai 1810 gebildete revolutionäre Regierungsjunta von Buenos Aires (Junta Provisional Gubernativa) über eine Übersetzung der nordamerikanischen Verfassung von $1787 .^{42}$ Diese stammte entweder von Mariano Moreno, dem Sekretär der Junta, oder von Alexander Mackinnon, dem Vorsitzenden des Kommittees der englischen Kaufleute in Buenos Aires. ${ }^{43}$ Neben solchen ersten spanischsprachigen Übersetzungen, Kommentierungen, selbständigen Untersuchungen nutzten die Anführer der Emanzipationsbewegung auch englischsprachige Dokumente aus den Vereinigten Staaten: Als Vordenker der Mairevolution verfügte Mariano Moreno neben einer Abschrift der nordamerikanischen Verfassung auch über die von Thomas Jefferson formulierte Unabhängigkeitserklärung. Das nordamerikanische Beispiel beeinflusste außerdem in der Peripherie des damaligen Vizekönigreich des Río de la Plata die Anführer der Unabhängigkeitsbewegung; so bezogen sich auch José Gaspar de Francia im späteren Paraguay und José Artigas in Uruguay auf das Vorbild der Vereinigten Staaten und ihrer Gründerväter. ${ }^{44}$

Juan Pablo Viscardo y Guzmán, Carta dirijida a los españoles americanos, in: Mario Rodríguez, La Revolución Americana de 1776 y el mundo hispánico. Ensayos y Documentos, Madrid 1976, S. 66 ff., 71 f.; zur Wirkung dieses Aufrufs in Spanischamerika: Zermeño Padilla, Historia, (Fn. 29), S. $135 \mathrm{ff}$.

Constitución Federativa asentada por la Convención del 17 de Sept.de 1787 in: Sampay, (Fn. 35), S. $89 \mathrm{ff}$.

Dazu Sampay (Fn. 35), S. 16, 89.

44 Mario Rodríguez, La Revolución Americana de 1776 y el mundo hispánico (Fn. 31), S. 41. 
Befördert durch den nordamerikanischen und französischen Einfluss, findet sich der Singular-Begriff „Freiheit“ (libertad) in den frühen Quellen häufig; zunächst in einer politischen Bedeutung, wie sie exemplarisch der liberale Revolutionär und Publizist Bernardo de Monteagudo hervorhob: zum einen im Sinne der Unabhängigkeit des bisherigen Vizekönigreichs vom Mutterland; zum anderen gegen die angeblichen Feinde der Freiheit im Inneren, die sich an den zahlreichen Erhebungen gegen die Zentralregierung in Buenos Aires beteiligten. ${ }^{45}$ Ebenfalls beeinflusst von den Vordenkern der französischen Revolution und den Gründern der Vereinigten Staaten, spielte ferner der republikanische Tugendbegriff eine starke Rolle, den die Kreolen im Sinne einer sowohl individuellen wie staatlichen „Freiheit“ für unverzichtbar hielten. ${ }^{46}$ Freiheit, wirkliche Freiheit bedeutet demnach Zügelung individueller Impulse durch die Vernunft, was den Menschen vom Sklaven unterscheide; ebenso wie es zur Veräußerung der Freiheit und zum Sklaventum führe, wenn der Einzelne, gesteuert durch seine Instinkte, sich gegen die Ordnung erhebe und den Gesetzen den Gehorsam verweigere. ${ }^{47}$

Der Hinweis auf die Freiheit sollte in den zahlreichen Dokumenten unmittelbar nach der Mairevolution des Jahres 1810 die Erhebung gegen die spanische Krone rechtfertigen, weshalb sich die Proklamationen zunächst bevorzugt gegen die „Tyrannei“ der spanischen Krone und eine aus Sicht der Kreolen illegitime Herrschaftsanmaßung wandten: Die spanischen Könige hätten, nicht zufrieden mit der ausführenden Gewalt, die gesetzgebende Gewalt usurpiert, die nun den Völkern in Spanien und Amerika zurückgegeben worden sei. $^{48}$ Damit kehrten die Revolutionäre in Argentinien zum einen die ihnen bekannte Argumentation der Spanier um, die sich zu diesem Zeitpunkt auf der Halbinsel militärisch und

Bernardo de Monteagudo, Clasificación y continuación del artículo de ciudadanía (1812), in: José Carlos Chiaramonte (Fn. 24), S. 358, zu den Bürgerrechten, die demjenigen zu verleihen seien, der das Vaterland gegen innere Verschwörung und Angriffe auf die Freiheit (,,contra los agresores de la libertad") verteidige.

So in der sechsten ergänzenden Note des Verfassungsentwurfs von 1811, „Proyecto de Constitución Provisoria, y advertencia a los comisarios diputados y suplentes, para el Congreso“, u.a. mit Hinweis auf Jean-Jaques Rousseau: „(...) a no confundir la libertad con la licencia, la subordinación con la esclavitud, la independencia é igualdad con la anarquía“, in: Sampay, (Fn. 35), S. 106.

Bernardo de Monteagudo, Observaciones didácticas (1812), in: Chiaramonte (Fn. 24), S. 360 f.: ,(...) la libertad no es sino ejercicio de la razón misma (....), pues la sujeción a un impulso contrario al orden es esclavitud, y sólo el que obedece a las leyes que se prescribe en una justa convicción goza de verdadera libertad“.

So die Einleitung zum Verfassungsentwurf von 1811 (Fn. 36), S. 101 ff.; zu diesem Argumentationsmuster in Argentinien und anderen Teilen Spanischamerikas: Javier Fernández Sebastián, Liberalismos nacientes en el Atlántico iberoamericano: „liberal“ como concepto y como identidad política, 1750-1850, in: Jahrbuch für die Geschichte Lateinamerikas 45 (2008), S. 149 ff., speziell $164 \mathrm{ff}$. 
weltanschaulich gegen die Herrschaftsanmaßung der Familie Bonaparte zur Wehr setzten. Zum anderen knüpften sie an das Konzept einer ,limited constitution“ an, den die Gründerväter der Vereinigten Staaten mit dem Freiheitsgedanken verknüpft hatten: die Verfassung als Ausdruck der Souveränität des Volkes in der Republik, um auf Dauer einer Despotie und Tyrannei des Herrschers vorzubeugen. ${ }^{49}$ Im Verfassungsentwurf von 1811 wird in diesem Zusammenhang, wie zuvor auf dem Kongress von Philadelphia (1787), zugleich auf eine mögliche Tyrannei der Mehrheit und des Gesetzgebers hingewiesen (Art. 16 S. 5). Auch wenn der Ausgangspunkt dieses frühen argentinischen Konzepts politischer Freiheit noch in der christlich-naturrechtlichen Verbindung lag, den das Widerstandsrechts mit einem höchsten, absoluten Zweck des Staates einging, enthält es im Kern bereits das liberal-staatliche Prinzip der individuellen Freiheit in einem negativen Sinne, als Abwehrrecht gegen den unrechtmäßigen Eingriff der öffentlichen Gewalten überhaupt. Diesen allmählichen Übergang bestätigt auch das ,,vorläufige Regierungsstatut“ der Triumviratsregierung von 1811, wenn es den Widerstand mit dem Eintreten für das ,,allgemeine Wohl, die Freiheit und das Glück der amerikanischen Völker" rechtfertigt, wobei sich dies zunächst noch stärker auf das Handeln der Regierung als auf ein verfassungsmäßiges Recht des einzelnen Bürgers bezieht. ${ }^{50}$ Dagegen bekräftigte die Junta von Buenos Aires in ihrem „Statut zur Gewaltenteilung“ (1811) ausdrücklich das Recht jedes Einzelnen, den Schutz seiner unveräußerlichen Rechte selber in die Hand zu nehmen, wenn die Vertreter des Volkes hierzu nicht mehr in der Lage seien. ${ }^{51}$ Noch handelte es sich um ein Widerstandsrecht, dass gegen Tyrannei und Herrschaftsanmaßung geltend zu machen war und ausnahmsweise eine ansonsten rechtswidrige Handlung legitimierte, aber bereits im Sinne eines universalen, für alle Menschen (,los hombres“) geltenden Freiheitsanspruches formuliert wurde. In dem Maße, wie in einer verfassungsmäßigen Ordnung solche Notstandsmaßnahmen dann als überflüssig galten, ging der Schutz vor Willkür - zumindest theoretisch - in ein verfahrensmäßig abgesichertes individuelles Abwehrrecht gegen jede Form staatlicher Diskriminierung über.

c. Bürgerliche Freiheit: Ideengeschichtlich wie politisch folgte in Argentinien auf die Erhebung eines politischen Freiheitsanspruchs, in dem sich das christliche Naturrecht und ein früher liberaler Schutzgedanke gegen staatliche Willkür verbanden, sogleich die Forde-

49

Vgl. Einleitung zum Verfassungsentwurf von 1811: „La primera atención de una Constitución civil, es reglar el govierno executivo, por que siendo arbitrario, breve será despótico, y tiranico“ (Fn. 36), S. $101 \mathrm{f}$.

50

Einleitung zum „Estatuto provisional del presente gobierno“ vom 22. 11. 1811, in dem die Regierung den Widerstand damit begründet, ,que su resistencia no conoce otro principio que el bien general, la libertad, y la felicidad de los pueblos americanos“, in: Sampay, (Fn. 35), S. 118.

Einleitung zum „Reglamento de la división de poderes sancionado por la Junta Conservadora“ vom 30.9.-29.10.1811, in: Arturo Enrique Sampay (Fn. 35), S. 110. 
rung nach „,bürgerlicher Freiheit“ (libertad civil). In den Stellungnahmen der Gründergeneration und den frühen Dokumenten der unabhängigen Republik lässt sich diese Weiterung gut nachvollziehen. Während die Unabhängigkeit des ehemaligen Vizekönigreichs Río de la Plata vom Mutterland noch nicht gesichert, speziell im Norden bis in die 20er Jahre des 19. Jahrhunderts stark bedroht erschien, sorgten sich die wechselnden Revolutionsregierungen in Buenos Aires außerdem über immer neue Unruhen und regionale Abspaltungstendenzen: so im späteren Paraguay und Uruguay. Dies erklärt, abgesehen vom Einfluss der französischen Revolutionäre, die starke Betonung der Freiheit des Einzelnen als „Bürger“ (ciudadano) im Inneren des sich neu konstituierenden argentinischen Staates. Hierfür steht die Gegenüberstellung der „,bürgerlichen Freiheit“ (libertad civil) und der „natürlichen Freiheit“ (libertad natural) in den „Didaktischen Erwägungen“ des Bernardo de Monteagudo: Erstere sei, im Unterschied zum unbeschränkten Freiraum des Einzelnen in seinem „wilden Naturzustand“, an die gesellschaftliche Konvention zurückgebunden, gründe sich in einer gegenseitigen Übereinkunft und beuge der Gewaltanwendung vor. ${ }^{52}$ Charakteristisch für dieses Freiheitskonzepts ist, dass die bürgerliche Freiheit immer wieder mit dem Terminus „Sicherheit“ (seguridad) korrespondiert, oder sogar synonym mit ihm gebraucht wird. Beide werden als Obergriff für die besonders zu schützenden privaten Positionen wie Eigentum und Rechtsgleichheit verwandt. ${ }^{53}$ Dies gilt nicht nur für Bernardo Monteagudo, sondern auch für die Triumviratsregierung von 1811, wenn sie bürgerliche Freiheit und individuelle Sicherheit gleichsetzt. ${ }^{54}$

Systematisch erscheint diese „,bürgerliche Freiheit“ zumindest in den ersten amtlichen Quellen den einzelnen Ausprägungen individueller Freiheit vorgeordnet. Ihre Gewährleistung steht im Mittelpunkt der Bestimmung von Staat und freiheitlicher Verfassung überhaupt, soweit diese dem "Glück der Nation“ verpflichtet sind. ${ }^{55}$ Deutlich tritt noch die Verbindung zum naturrechtlichen Staatszweckgedanken zutage, der sich in der Verpflichtung auf das „Glück der Nation“ mit dem nordamerikanischen ,pursuit of happiness“ ver-

Bernardo de Monteagudo, (Fn. 37), S. 360 f.

Bernardo de Monteagudo, (Fn. 37 ), S. 360, 364 ff. Vorbild ist die Proklamation der „liberté, égalité, sûreté, proprieté" durch die Französischen Revolutionäre, vgl. Art. 2 der Menschen- und Bürgerrechteerklärung in der französischen Verfassung von 1791; dann auch Art. 1 der Verfassung des Jahres III (1795), in: Charles Debbasch / Jean-Marie Pontier (Hg.), Les Constitutions de la France, 3.Aufl., Paris 1996, S. 9 bzw. S. 60.

54

Gemäß der Einleitung des „Decreto de seguridad individual“ vom 23.11.1811: „La posición de este derecho, centro de la libertad civil, y principio de todas las instituciones sociales, es lo que se se llama seguridad individual“", in: Sampay, (Fn. 35), S. 120.

Vgl. das „Reglamento de la division de poderes sancionado por la Junta Conservadora“ vom 30.9.-29.10.1811: ,...) una Constitución liberal, y equitativa, que perfeccionada por el futuro congreso labre la felicidad de la nación, afianzando la libertad justa del ciudadano, y poniendo trabas á la arbitrariedad de los depositarios del poder", in: Sampay, (Fn. 35), S. 109. 
bindet. Den Rang der „,bürgerlichen Freiheit“ verdeutlicht, dass sie hier - gleichbedeutend mit Freiheit überhaupt - ohne Attribut proklamiert wird. Dieselbe Wertschätzung drückt die Triumviratsregierung aus, wenn sie die „libertad civil“ als Oberbegriffs für die gleichfalls unveräußerliche Rechte fasst, die gleichsam deren Unterfälle bilden: so das Recht auf Leben, die persönliche Ehre, das Eigentum. ${ }^{56}$ In den späteren Texten wird sie immer häufiger als eine Ausprägung der Freiheit unter mehreren erwähnt. Eine besondere Wertschätzung erfährt sie nun in jenen Lebensbereichen, die wie die Pressefreiheit aus Sicht der kreolischen Elite besondere Bedeutung für eine öffentliche Meinungs- und Willensbildung hatten. 57

Seit Mitte des zweiten Jahrzehnts setzte sich in den Statuten, Entwürfen und in den ersten Verfassungstexten, die zwar verabschiedet wurden, sich jedoch gegen die Provinzen des Landesinneren nicht hatten durchsetzen lassen, ein etwas veränderter Sprachgebrauch durch: Freiheit wurde im Singular und dabei zunehmend ohne Attribut (,libertad“) verwandt und in einer Generalklausel zusammen mit den anderen naturrechtlich abgeleiteten Individualrechten den übrigen Bestimmungen vorangestellt. ${ }^{58}$ Ein auch praktisch bedeutsamer Fall war das „Gesetz über die Freiheit der Leibesfrucht“ von 1813, wonach alle neu geborenen Sklavenkinder frei sein sollten, während außerdem bereits die Einfuhr von Sklaven in die Provinzen des Río de la Plata untersagt war. ${ }^{59}$ Auch die gesonderten Verfügungen und Dekrete, die der gleichsam existentiellen Bedeutung der Freiheit Ausdruck verleihen sollten, gebrauchten den Terminus „Freiheit“ seit dieser Zeit immer häufiger ohne „Todo ciudadano tiene un derecho sagrado á la protección de su vida, de su honor, de su libertad y de sus propiedades. La posición de este derecho, (es) centro de la libertad civil (...)“ (Fn. 54), S. 120.

Jeweils wortgleich die Verfassung von 1819, „Constitución de las Provincias unidas en Sud América“ im 5. Abschnitt, 2. Kap., Ziff. CXI und die Verfassung von 1826, „Constitución sancionada por el Congreso General Constituyente de 1824 - 127“" vom 24.12.1826 in Art. 161: „La libertad de publicar sus ideas por la prensa es (...) esencial para la conservación de la libertad civil en un Estado“, in: Sampay, (Fn. 35), S. 275 bzw. S. 320.

So, wenn auch mit Abweichungen im Einzelnen: Präambel zum „Estatuto provisional para la dirección y administración del Estado, dado por la Junta de Oberservación“" vom 5.5.1815 und 1. Abschn., 1. Kap., Art. 1des „Estatuto provisional, dado por la Junta de Oberservación y aprobado con modificaciones por el Congreso de Tucumán" vom 22.11.1816, in: Sampay, (Fn. 35), S. 211 bzw. S. 233; ferner 5. Abschnitt, 2. Kap., Ziff. CXI der Verfassung von 1819 und Präambel zur Verfassung von 1826, ebda., S. 275 bzw. S. 307.

Asamblea del año XIII, „Libertad de vientres“ vom 3.2.1813 bzw. „Prohibición de introducir esclavos“ vom 14.5.1812, in: José Carlos Chiaramonte, Ciudades, provincias, Estados (Fn. 24), S. 418 f. bzw. S. 419 f. 
Attribut - teilweise aber auch schon davor, wie in jenem bekannten Dekret der vorläufigen Regierungsjunta, mit dem sie die Tributleistungen der Indigenen untersagte. ${ }^{60}$

Auffallend ist, dass die argentinischen Staatengründer in den einleitenden Proklamationen, die sie noch mit revolutionärem Schwung und beeinflusst durch das französische Beispiel formulierten, diese Aufzählung regelmäßig als Menschenrechte (,derechos del hombre") bezeichneten: so in den Präambeln zum Statut von 1815 und zur Verfassung von 1826. Dort jedoch, wo diese Generalklausel offenbar eine auch juristische Wirkung haben sollte, bezieht sie sich enger auf die Bewohner bzw. auf die Bürger des argentinischen Staates (,los habitantes del Estado“, „los miembros del Estado“): so in den entsprechenden Artikeln des Statuts von 1816 und der Verfassung von 1819. Eine universale Bedeutung hatten „Freiheit, Gleichheit, Eigentum“ demnach insofern, als sich die Kreolen am Río de la Plata bewusst als Teil einer politischen und ideengeschichtlichen Entwicklung sahen, die sie mit den politischen Umbrüchen in der westliche Hemisphäre verband. Zugleich erhielt das Bekenntnis $\mathrm{zu}$ diesen Rechten jedoch eine engere, aber auch konkretere staatliche Funktion, weil ihr Schutz als wesentliche Voraussetzung eines künftigen argentinischen Nationalstaates galt.

Unter den konkreteren Ausprägungen des Freiheitsbegriffs seien folgende hervorgehoben:

d. Presse- und Religionsfreiheit: Ebenso wie in anderen Revolutionen, die zur Ablösung des Ancien Régime führten, hat auch im Zusammenhang mit der argentinischen Mairevolution die Meinungs- und Pressefreiheit eine zentrale Rolle gespielt. Dies belegt deren häufige Erwähnung in den Dokumenten dieser Zeit, in denen „Pressefreiheit“ (libertad de la prensa, libertad de imprenta) oft synonym zu „Meinungsfreiheit“ (libertad de pensar) gebraucht wurde und diese regelmäßig mit einschloss. So in der Begründung zum Dekret des Triumvirats über die Pressefreiheit mit den Worten des Deán Funes: „Ohne Pressefreiheit gibt es keine Meinungsfreiheit.“ Beide gehörten ebenso wie das Eigentum zur menschlichen Person; denn es handle sich um die wesentlichsten Ausdrucksformen der Persönlichkeit. $^{61}$

60

Junta Provisional Gubernativa de las Provincias Unidas del Río de la Plata am 1.9.1811, in: José Carlos Chiaramonte, (Fn. 24), S. 420 f.: „,...) que se promoviese por todos caminos su (de los habitantes) ilustración, su comercio, su libertad, para destruir y anaquilar en la mayor parte de ellos las tristes ideas, que únicamente les permitía formar la tiranía“.

61

Gregorio Funes, Discurso sobre la libertad de la prensa presentado a la Junta Superior de Gobierno (1811), in: José Carlos Chiaramonte (Fn. 25), S. 328; m.w.N. zur vielfältigen Begriffswahl der Kreolen: Noemí Goldman, Legitimidad y deliberación: el concepto de opinión pública en Iberoamérica, 1750-1850, in: Jahrbuch für die Geschichte Lateinamerikas 45 (2008), S. 221 ff., speziell 230 ff.: Gebräuchlich waren u.a. auch „la libertad de opinar o de opinión“, „la libertad de hablar y escribir ilimitadamente“. 
Trotz des revolutionär-liberalen Schwungs der Erhebung, insbesondere in Buenos Aires, sah sich die kreolische Elite dennoch zu einem politisch-gesellschaftlichen Kompromiss gezwungen. Sie musste Rücksicht auf das traditionelle Bekenntnis der Bevölkerung zum römisch-katholischen Glauben nehmen, den die Unabhängigkeitsrevolution eher zu stärken als zu schwächen schien: Nicht selten wurden die Revolutionsfeiern oder die Siege der Aufständischen mit Gebeten, Messfeiern und Prozessionen begangen, weil die Bevölkerung die Erfolge auf das Wirken der göttlichen Gnade zurückführte. ${ }^{62}$ Diese Rücksichtnahme hebt sich stark von der Haltung der französischen Revolutionäre nach 1789 ab, ähnelt dagegen sehr jenem Kompromiss, den sowohl die spanische Konstituante in ihrem Reformwerk (1810-1812) wie auch die übrigen jungen Republiken in Lateinamerika eingingen. ${ }^{63}$ Diese Parallele betrifft, abgesehen von einer vergleichbaren Verwurzelung in der katholisch-scholastischen Tradition, auch einen politischen Gedanken: Je stärker die Erschütterungen durch die politischen Leidenschaften und den Kampf um die Unabhängigkeit am Río de la Plata, desto wichtiger sei es, die ungebändigte Freizügigkeit des Einzelnen durch eine moralische und sittliche Rückbindung an den einen, gemeinsamen Glauben zu mäßigen. ${ }^{64}$ Die argentinischen Staatengründer haben sich daher in ihren Statuten, Entwürfen und Verfassungstexten mit Blick auf das besonders schwierige Verhältnis der Pressefreiheit zur Religionsfreiheit an den Überlegungen der spanischen Cortes orientiert. Wegen der anderen Ausgangslage traten für diesen Gegenstand die im übrigen einflussreichen Vorbilder aus Frankreich und den USA in den Hintergrund. Einerseits gilt die Presse- (und Meinungs)freiheit in den hier relevanten argentinischen Proklamationen als natürliches, vorstaatliches Menschenrecht und wegen dieser naturrechtlichen Ableitung und seiner Schlüsselrolle für die Wahrung der Freiheit überhaupt grundsätzlich als unantastbar, wie es die Verfassungen von 1819 und 1826 besonders klar ausdrückten. ${ }^{65}$ Andererseits steht die Presse- und Meinungsfreiheit hier wie in den übrigen Texten unter einem Vorbehalt zu-

M.w.N. und Beispielen: Geneviève Verdo, La bannière, le sabre et le goupillon: les cérémonies patriotiques dans l'indépendance du Rio de la Plata (1808-1821), in: Revue Historique 296 (1996), S. 407 ff., 424 ff. unum: revoluciones constitucionales y disgregación de las Monarquías iberoamericanas, in: Jahrbuch für die Geschichte Lateinamerikas 45 (2008), S. 57 ff., speziell S. 73 ff.

Gazeta de Buenos Ayres, Reflexiones sobre la causa de la desigualdad de las fortunas, y sobre la importancia de las ideas religiosas para mantener el orden público, in: José Carlos Chiaramonte (Fn. 24), S. $311 \mathrm{f}$. esencial para la conservación de la libertad civil en un Estado“ (Fn. 57), S. 275 bzw. S. 320. 
gunsten des Gesetz- bzw. Verordnungsgebers. ${ }^{66}$ Die „libertad de imprenta“ findet ihre Grenzen nicht nur in anderen individuellen Rechten; vielmehr auch im Schutz überragender Gemeinschaftsgüter, wozu die argentinischen Staatengründer außer der öffentlichen Ruhe insbesondere den Schutz des katholischen Glaubens zählten. ${ }^{67}$

Ideengeschichtlich belegt diese Position wie kaum ein anderer Gegenstand die besondere Nähe zur spanischen Rechts- und Glaubenstradition. Trotz der starken Einflüsse sonst, besteht hier ein erheblicher Unterschied des argentinischen zum nordamerikanischen Konzept von Freiheit. Denn in den Vereinigten Staaten setzte sich eine Tendenz zur Privatisierung der Religionsausübung durch, wofür Ansätze bereits in der englischen Rechtsgeschichte bestanden. Die Religion galt dort zwar nach wie vor als das Höchste und Absolute, aber als Sache des Einzelnen, vor der jede Art des sozialen und staatlichen Gebildes zu etwas Relativem wird. Somit ist auch der jedem Individuum eigene absolute Wert in seiner privaten Sphäre durch die Religionsfreiheit als das erste aller Grundrechte geschützt. ${ }^{68}$ In diesem Sinne avancierte das Verbot, eine Staatskirche zu gründen, in den USA gleichsam zu einem „Grundrecht aller Grundrechte“, was sich auch in einer im Vergleich zur europäischen Geschichte geringen Neigung zu weltanschaulich-religiösen Auseinandersetzungen niederschlug. ${ }^{69}$ Dagegen galt den Gründern der argentinischen Republik die Verteidigung des katholischen Glaubens und eines bestimmten Moralverständnisses als öffentliche Angelegenheit schlechthin. ${ }^{70}$ Somit gehörte es in den ersten Jahrzehnten nach der Mai-Revolution zum festen Bestandteil der offiziellen Texte, dass sie die öffentlichen Gewalten, aber auch die Einzelnen auf die katholische Staatsreligion verpflichten: Der Staat sei eine enge

In den Texten der Republik seit Art. 13 S. 1 des Verfassungsentwurfs von 1811: „Se dará la imprenta libre en los terminos, que en su ultimo decreto sobre la materia lo establece Superior Govierno“ (Fn. 36), S. 104; so auch Art. 13 des konservativeren Gegenentwurfs (1815) zu den republikanischen Texten: „, Proyecto de Constitución monárquica de Rivadavia y Belgrano“, in: Arturo Enrique Sampay, Las Constituciones de la Argentina (Fn. 35), S. 210.

So im „Decreto de la libertad de imprenta“ der Triumviratsregierung vom 26.10.1811, nach dem Vorbild des Pressedekrets der spanischen Cortes: „Todo hombre puede publicar sus ideas libremente, y sin prévia censura“ (Art. 1 S. 1). „El abuso de esta libertad es un crímen. Su acusación corresponde á los interesados, si ofende derechos particulares; y a todos los ciudadanos, si compromete la tranquilidad pública, la conservación de la religión católica, ó la constitución del estado.“ (Art.2), in: Sampay (Fn. 35), S. 121; wortgleich jeweils im 7. Abschnitt, 2. Kap. des „Estatuto provisional para la dirección y administración del Estado, dado por la Junta de Oberservación“ vom 5.5.1815 und des „Estatuto provisional, dado por la Junta de Oberservación y aprobado con modificaciones por el Congreso de Tucumán“ vom 22.11.1816, in: Sampay, ebda., S. 228 bzw. S. 252.

Carl Schmitt, Verfassungslehre, 5. Aufl., Berlin 1970, S. 158 f.

Ernst Fraenkel, Das amerikanische Regierungssystem, in: ders. (Hg.), Gesammelte Schriften, Bd. 4: Amerikastudien, Baden-Baden 2000, S. 470 f.

70

Exemplarisch die Argumentation des Gregorio Funes (Fn. 61), S. 329 ff. 
Verbindung mit der einen und wahren Religion eingegangen, dass auch nur diese eine als Bekenntnis gelten dürfe. ${ }^{71}$ Der katholische Glauben sei auch der des Staates, der ihn schütze sowie die Kirchen, die Geistlichen und den Gottesdienst erhalte. ${ }^{72}$ Darüber hinaus solle auch jeder einzelne Bewohner des Staatsgebietes Gottesdienst und Staatsreligion achten $^{73}$ - und zwar unabhängig von seinen privaten Anschauungen. ${ }^{74}$ Die herausragende Stellung der Staatsreligion wird gerade in diesen beiden Verfassungen $(1819,1826)$ besonders deutlich, da sie deren Proklamation quasi an den Anfang und damit den übrigen Rechten und Pflichten voran stellten.

e. Eigentumsfreiheit: Die führenden Eliten am Río de la Plata rezipierten jene liberale Eigentumskonzeption, wie sie sich mit Aufklärung und Physiokratie zuvor in Europa durchgesetzt hatte. Dieses Konzept verband sich mit einer ihrer Rezeption günstigen Erfahrung der kreolischen Eliten: Ihr Einfluss beruhte auf Eigentum, so dass sie Freiheit dinglich verstanden und das Verfügen über ihr Vermögen als eigentlichen Maßstab ihrer „Libertät“ begriffen. Dies verbesserte die Chancen für eine Rezeption jener „,neuen“ Wertschätzung wirtschaftlicher Freiheit gegenüber Merkantilismus und Kameralismus, wie sie über Europa nun auch in Übersee Resonanz fand. Wie die höchstpersönlichen Rechte sonst, sollte auch das Eigentum einen absoluten Schutz erfahren, da der Mensch es durch seine eigene Kraft und Personalvermögenheit hervorbringt und formt. ${ }^{75}$ Die Liberalität besteht darin, dass sich der Mensch der Aufklärung nunmehr nicht nur gegenüber der Natur als frei versteht, sondern auch das Recht zu haben glaubt, über sie zu herrschen: „Das Eigentumsrecht ist dabei der intensivste Ausdruck dieses Herrschaftsanspruchs“. ${ }^{76}$ Der sich hierin ausdrückende gewandelte Bezug zur dinglichen Welt überhaupt war in Argentinien besonders plausibel -

Art. 17 des Verfassungsentwurfs von 1811 (Fn. 36), S. 105; ferner Gregorio Funes, (Fn. 61), S. $328 \mathrm{ff}$.

3. Kap., Art. 1 Abs. 1 des „Proyecto de Constitución para las Provincias del Río de la Plata, formado por una comisión especial designada por el segundo triumvirato“ von 1813, in: Sampay (Fn. 35), S. 191.

Gleich lautend: 1. Abschnitt, 2. Kap., Art. 2 des vorläufigen Statuts von 1815 und 1. Abschn., 2. Kap., Art. 2 des vorläufigen Statuts von 1816, in: Sampay (Fn. 67), S. 212 bzw. S. 233.

1. Abschn., 1. Kap. der Verf. von 1819 und Art. 3 der Verfassung von 1826 (Fn. 57), S. 269 bzw. S. $309 \mathrm{f}$.

Stellvertretend Johann August Schlettwein, Grundfeste der Staaten oder die politische Ökonomie (1779), Frankfurt am Main 1971, S. 113; dazu Diethelm Klippel, Der Einfluß der Physiokraten auf die Entwicklung der liberalen politischen Theorie in Deutschland, in: Der Staat 23 (1984), S. $208 \mathrm{ff}$.

Damian Hecker, Das Eigentum, einst Gottesgabe, heute Herrschaftsrecht: die Entwicklung des Eigentumsbegriffs zum Sachherrschaftsrecht als Ausdruck eines besonderen Herrschaftsdenkens, in: Zeitschrift für Neuere Rechtsgeschichte 10 (1988), S. 181, 185. 
angesichts der Weite des Raums, den es in der argentinischen Pampa zu besiedelnden galt sowie der Bedeutung von Handel und Gewerbe in den aufstrebenden Städten. Schon die gestiegene wirtschaftliche Bedeutung des Eigentums sprach daher für dessen Aufwertung. Denn ein vorstaatliches Menschenrecht, das jeder gesellschaftlichen Übereinkunft vorausgeht, ist schon theoretisch in seinem Kern hoheitlichen Eingriffen entzogen. In diesem Sinne proklamierten die frühen amtlichen Texte der Argentinier, wie die dort verankerte, bereits erwähnte Generalklausel belegt, das Eigentum stets als eines jener besonders geschützten „Rechte des Menschen“ bzw. der Bewohner des Staatsgebietes. Der enge Zusammenhang mit dem Begriff „libertad“ unterstreicht, dass das Recht auf Eigentum den Menschen und Bürgern aufgrund ihrer natürlichen vorstaatlichen Freiheit zustehen sollte. Dieser besonderen Qualität wegen standen Eingriffe unter einem besonderen gesetzlichen oder richterlichen Vorbehalt, wie es die Verfassung von 1819 ausdrücklich festlegte. ${ }^{77}$

\section{Ergebnis: Freiheit versus Gleichheit}

Der in diesem Zusammenhang unerlässliche Blick auf die amtlichen Texte belegt, dass in Argentinien bis zum dritten Jahrzehnt des 19. Jahrhunderts zumindest im öffentlichen Sprachgebrauch jene ständischen Einzelfreiheiten (libertates) dem modernen nachrevolutionären Konzept der Freiheit des Einzelnen (libertad) gewichen waren. Wie den Dokumenten zu entnehmen ist, meint ,libertad“ hier nicht eine bloße Verdichtung oder Summierung der alten ständischen Fueros. Denn zugleich belegen die frühen Statuten, Entwürfe und Verfassungen, dass die Kreolen - wenn auch unter Einfluss französischer und nordamerikanischer Muster - einen neuen, ja revolutionären Anspruch erhoben. Denn neben jener Freiheit proklamierten sie zugleich zu ihrer individuellen Sicherheit die Teilung der Funktionen, eine politische Teilhabe sowie den Schutz der Menschen- und Bürgerrechte. Auch die für den modernen Freiheitsbegriff kennzeichnende Verrechtlichung lässt sich hier nachverfolgen.

Auf einem anderem Blatt steht aber, ob sich in diesem semantischen Übergang durchgehend ein klarer Gegensatz von „Freiheit überhaupt“ und traditionellen „Freiheiten“ ausdrückte; und ob die bisher nicht Berechtigten tatsächlich in den Genuss dieser neuen „libertad“ kamen, so dass eine neuartige Verbindung von Gleichheit und Freiheit die überkommenen ständischen Rechte und Privilegien ablöste. Dies schließt jener Übergang nämlich streng genommen mit ein. ${ }^{78}$ In der argentinischen Realität bestand ein quasi feudaler kreolischer „Geburtsadel“ fort, der als Stand weiterhin auf seine „rechtmäßigen Freiheiten“ miembros del Estado no pueden ser privados de ella ni gravados en sus facultades sin el consentimiento del Cuerpo Legislativo, ó por un juicio conforme à las leyes“ (Fn. 57), S. 276. 
bestand, nämlich jene vielfältigen ökonomischen und politischen Privilegien der Kolonialgesellschaft. Bezeichnend ist, dass sich die Kreolen - das ist geschichtlich der Ausgangspunkt der Revolution - zuerst gegen die Vorteile der europäischen Spanier in Übersee wandten. Es ging ihnen kaum um die Ungleichheit innerhalb der überseeischen Gesellschaft, wie daher auch eine tatsächliche Änderung der gesellschaftlichen Verhältnisse nicht beabsichtigt war. Diese Ausgangslage war durchaus vergleichbar mit jener der nordamerikanischen Kolonien: Hier wie dort zielten die Aufständischen auf jene spezifischen Belange $a b$, die sie durch das Untertanenverhältnis zur Krone des Mutterlandes gefährdet sahen. So lag auch das eigentlich Revolutionäre an der Gleichheitsforderung darin, dass die bisherige Unterscheidung zwischen Krone und Untertanen beziehungsweise zwischen Metropole und Provinzen im Widerspruch zur natürlichen Ordnung stehe und daher Leben, Freiheit und Eigentum besser außerhalb als innerhalb des Königreichs und seiner Verfassung zu gewährleisten sei. ${ }^{79}$ Die zitierten argentinischen Generalklauseln nennen „Gleichheit“" (igualdad) wie die französischen Erklärungen der Menschen- und Bürgerrechte neben der ebenfalls naturrechtlich abgeleiteten Freiheit des Einzelnen. ${ }^{80}$ Wenn sich daher die Kreolen im Zuge der Emanzipationsbewegung immer wieder auf „Freiheit und Gleichheit“ in der Wortwahl der Französischen Revolution bezogen, hatte dies niemals eine wirklich egalitäre Bedeutung. Nur im Sprachgebrauch der liberalen Elite, nicht aber in der Alltagserfahrung der Argentinier bezog sich diese „Gleichheit“ als wesentliches Attribut auf den Bürger (ciudadano), der das Gegenbild zu den mit Sonderrechten ausgestatteten Privilegierten (privilegiados) verkörpern sollte, deren Bevorzugung als Inbegriff der Ungerechtigkeit im Alten Staat gegolten hatte. ${ }^{81}$ Es war Allgemeingut, dass die Freiheit in der Vernunft gründe, an der alle Menschen unterschiedslos teilhaben, weil sie ihr Handeln gemäß der Vernunft selber bestimmen können. Doch wenn die Kreolen dieses naturrechtliche Postulat theoretisch bekräftigten, folgerten sie daraus keineswegs eine gesellschaftliche oder politische Gleichheit.

Auch die Erfahrungen und Gewohnheiten sprechen dafür, dass der erwähnte begriffliche Übergang nicht in jeder Hinsicht die politisch-rechtlichen Vorstellungen der Zeitgenossen oder gar ihr Alltagsleben widerspiegelte. So versammelten sich selbst anlässlich der Revolutionsfeiern die Bürger der argentinischen Provinzstädte immer noch nach Korporationen geordnet, wie es dem traditionellen Brauch entsprach: Notabeln, Geistlichkeit,

Für Nordamerika: Willi Paul Adams, The first American Constitutions. Republican Ideology and Making of the State Constitutions in the Revolutionary Era, Chapel Hill (North Carolina) 1980, S. $171 \mathrm{f}$.

Vgl. Art. 6 S. 3 f. der französischen Erklärung der Menschen- und Bürgerrechte von 1789; deutlicher noch Art. 3 der gleichnamigen Erklärung, Acte constitutionell du 24 juin 1793: „Tous les hommes sont égaux par la nature et devant la loi“, Charles Debbasch / Jean-Marie Pontier (Fn. 53), S. 44. 
Richter und militärische Ränge fanden sich separat ein, getrennt ferner die Stadtbürger von den Bewohnern des Umlandes. ${ }^{82}$ Die - schließlich gescheiterte - Verfassung des Jahres 1819 gab den Delegierten der Körperschaften Heer, Geistlichkeit und Universitäten jeweils Sitz und Stimme im Senat. Dies spricht ebenso für einen fortbestehenden starken korporativistischen Geist wie die Gewohnheit mancher Verantwortlicher, die spanische Kolonialordnung auch nach der Mai-Revolution noch als ,unsere alte Verfassung“ zu qualifizieren. ${ }^{83}$ Die Wahl moderner Begriffe scheint vielfach aufgesetzt. Dazu gehört neben dem Singularbegriff „Freiheit“ in einem universalen revolutionären Sinne auch der „Bürger“ als Assoziation der „Freien und Gleichen“, die eine Nation bilden. Zumindest eilte diese Terminologie der gesellschaftlichen Entwicklung weit voraus. Dies galt in weit stärkerem Maße als in Buenos Aires vor allem für das konservativ geprägte Landesinnere der jungen Republik. 